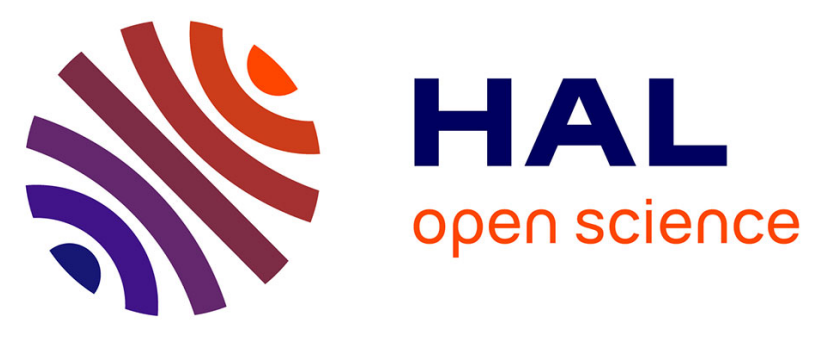

\title{
Advances in silicon surface texturization by metal assisted chemical etching for photovoltaic applications
}

Sylvain Le Gall, Raphaël Lachaume, Encarnacion Torralba, Mathieu Halbwax,

Vincent Magnin, Taha El Assimi, Marin El Fouchier, Joseph El Harari, Jean-Pierre Vilcot, Christine Cachet-Vivier, et al.

\section{To cite this version:}

Sylvain Le Gall, Raphaël Lachaume, Encarnacion Torralba, Mathieu Halbwax, Vincent Magnin, et al.. Advances in silicon surface texturization by metal assisted chemical etching for photovoltaic applications. 2017 IEEE 44th Photovoltaic Specialists Conference (PVSC), IEEE, Jun 2017, Washington, United States. 10.1109/pvsc.2017.8366525 . hal-01579151

\section{HAL Id: hal-01579151 \\ https://hal.science/hal-01579151}

Submitted on 30 Aug 2017

HAL is a multi-disciplinary open access archive for the deposit and dissemination of scientific research documents, whether they are published or not. The documents may come from teaching and research institutions in France or abroad, or from public or private research centers.
L'archive ouverte pluridisciplinaire HAL, est destinée au dépôt et à la diffusion de documents scientifiques de niveau recherche, publiés ou non, émanant des établissements d'enseignement et de recherche français ou étrangers, des laboratoires publics ou privés. 


\title{
Advances in silicon surface texturization by metal assisted chemical etching for photovoltaic applications
}

\author{
Sylvain Le Gall ${ }^{1}$, Raphaël Lachaume ${ }^{1}$, Encarnacion Torralba ${ }^{2}$, Mathieu Halbwax ${ }^{3}$, Vincent Magnin ${ }^{3}$, Taha \\ El Assimi ${ }^{2}$, Marin Fouchier ${ }^{3}$, Joseph Harari ${ }^{3}$, Jean-Pierre Vilcot ${ }^{3}$, Christine Cachet-Vivier ${ }^{2}$, Stéphane \\ Bastide $^{2}$ \\ ${ }^{1}$ Génie Electrique et Electronique de Paris, UMR-CNRS 8507, Centralesupelec, Univ. Paris-Sud, UPMC, France \\ ${ }^{2}$ Institut de Chimie et des Matériaux Paris-Est, CNRS, Univ. Paris-Est, France \\ ${ }^{3}$ Institut d'Electronique, Microélectronique et Nanotechnologies, UMR-CNRS 8520, Univ. Lille 1, France
}

\begin{abstract}
New Si processes based on Metal Assisted Chemical Etching (MACE) are explored for solar cells texturization. Pt and Au are considered as catalysts for MACE of $p$ and n-type Si substrates. $2 D$ band bending modeling at the nanoscale shows that $\mathrm{Pt}$ nanoparticles (NPs) make ohmic contacts and induce delocalized etching. Accordingly, coneshaped macropores, very efficient in reducing the reflectivity $(<5 \%)$ are obtained experimentally. On the contrary, Au with ntype Si leads to non-ohmic contacts and localized etching. On this basis, a novel strategy for $3 D$ pattern transfer into $S i$ with patterned nanoporous gold electrodes in a single step is developed.
\end{abstract}

\section{INTRODUCTION}

Silicon etching is a key process in the fabrication of $\mathrm{Si}$ microstructures that are essential for the development of several component families used in microelectronics, photonics and solar energy conversion. A large variety of efficient $\mathrm{Si}$ microstructuring technologies exists nowadays (e.g. wet/dry etching, photo/electron beam lithography). Their remarkable efficacy comes at the expense of numerous lithography (mask) and etching steps that are not suitable for industry, especially when cost and fabrication time are key aspects for Si solar cells manufacturing. A maskless technique with direct imprinting of patterns would dramatically simplify the fabrication of microstructures. However, eliminating the use of masks is extremely challenging and implies to move towards micromachining techniques.

In this context, MACE of Si has attracted considerable attention as an efficient way to produce Si nanostructures with high aspect ratio. Noble metals, including Ag, $\mathrm{Au}, \mathrm{Pt}, \mathrm{Pd}$, etc., are known to be effective catalysts for MACE [1], each one leading to different results in the (de)localized character of etching [2, 3]. The reason for this behavior may lie in the $\mathrm{Si} /$ metal Schottky junction properties that determine hole $\left(\mathrm{h}^{+}\right)$ injection into Si, which depends on the metal work function and on the doping type of $\mathrm{Si}$, as recently brought to attention by Kolasinki [4].

With the aim of developing new efficient texturization processes for Si solar cells, two MACE systems involving opposite metal/Si contact properties are investigated in this work.

\section{RESULTS AND DISCUSSION}

A. Surface structuration of p-type Silicon by MACE using Pt nanoparticles

First, we have experimentally studied the Pt nanoparticle/p-Si/HF system. Details of the experimental set-up and Si substrate can be found in reference [3]. Figure 1 shows cross-sectional Scanning Electron Microscopy (SEM) images of typical cone-shaped macrosctructures obtained by MACE with Pt NPs. A thick porous Si layer covers both the surface and the inner core. This is due to the delocalized character of p-Si etching using Pt as catalyst, as explained below.
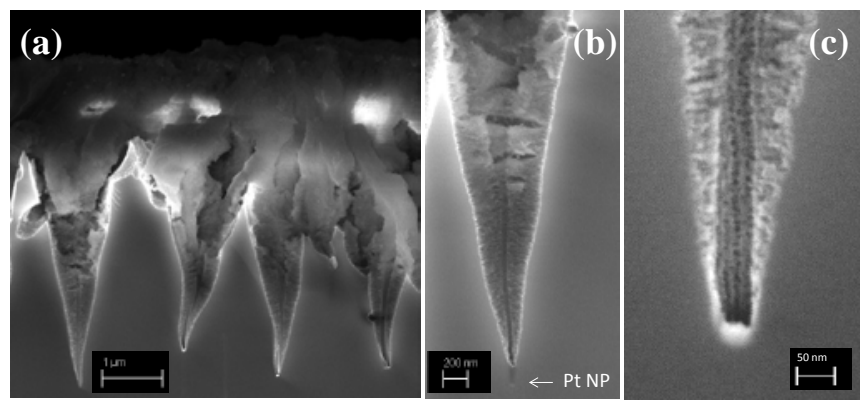

Fig. 1. SEM images in cross section of p-type (100) Si samples after MACE with Pt NPs; increasing magnification from (a) to (c).

To gain insights into this MACE process, 2D Numerical simulations of the valence band modulation at the Pt NP/pSi/electrolyte interfaces were carried out using a TCAD software. More details about the modeling and the modeled structure are given in the supporting information of [3].

Figure 2(a) shows a 3D plot of the Si conduction band (CB) and valence band (VB) modulations around the Pt NP (located at $\mathrm{x}=0.5 \mu \mathrm{m}$ ) for the system at equilibrium. The large difference between the work functions of the electrolyte $W_{E L}$ $(4.5 \mathrm{eV})$ and Pt $W_{P t}(5.6 \mathrm{eV})$ induces a modification of the band bending at the surface close to the NP. In this system, away from the Pt NP, i.e. at the p-Si/Electrolyte junction, we observe a Schottky energy barrier height of $0.48 \mathrm{eV}$ for $\mathrm{h}^{+}$ 
coming from the bulk. On the contrary, beneath the Pt NP, the $\mathrm{VB}$ is above the FL, indicating the presence of a strong accumulation layer of $\mathrm{h}^{+}$(ohmic contact).
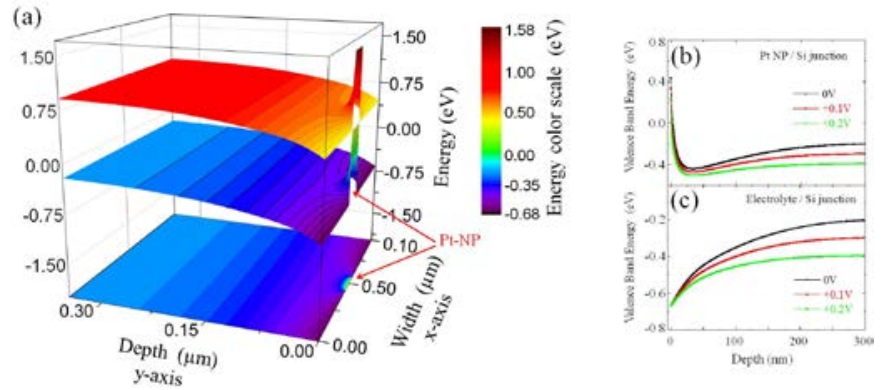

Fig. 2. Modelling of the band bending of a Pt NP/p-Si/Electrolyte device. (a) 2D profiles of $\mathrm{CB}$ and $\mathrm{VB}$ energies at the equilibrium $(0 \mathrm{~V})$. The VB energy is also projected on the bottom $(\mathrm{x}, \mathrm{y})$ plane. (b), (c) 1D profiles of the VB energy for different Pt polarization (b) under the Pt NP ( $x=50 \mathrm{~nm})$ and (c) under the Electrolyte $(\mathrm{x}=0 \mathrm{~nm})$.

Figures 2(b) and 2(c) show the VB depth profiles (y-direction) under equilibrium $(0 \mathrm{~V})$ and positive bias $(+0.1$ and $+0.2 \mathrm{~V}$ ) at two specific locations: (b) the middle of the Pt contact $(x=50 \mathrm{~nm})$ and (c) the Electrolyte far from $\mathrm{Pt}$ $(\mathrm{x}=0 \mathrm{~nm})$. This positive bias can be identified with the oxidant power of $\mathrm{H}_{2} \mathrm{O}_{2}$ during MACE. Due to the ohmicity of the $\mathrm{Pt}$ contact, the entire voltage drop falls at the p-Si/Electrolyte interface under positive bias, and the VB in the bulk follows the applied polarization by the same extent. Consequently, the applied voltage, or the oxidizing power of $\mathrm{H}_{2} \mathrm{O}_{2}$, reduces the barrier height of the Si/Electrolyte junction.

On the basis of the experimental results and numerical simulations of both the VB and the space charge region (SCR) in Si and around the Pt NP, the scheme of Figure 3(b) is proposed to rationalize the formation of cone-shaped pores by MACE with Pt NPs.
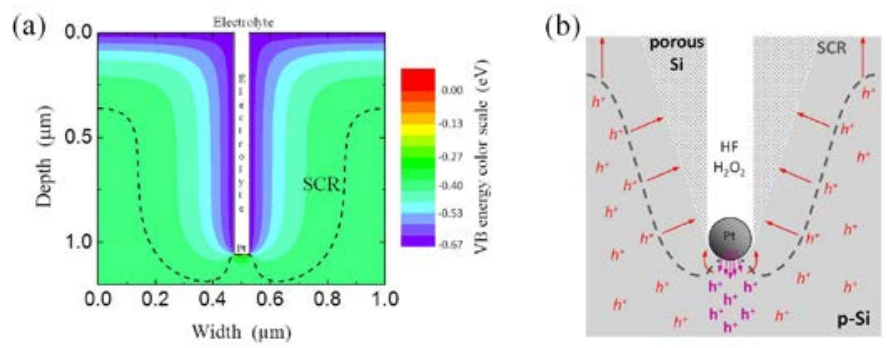

Fig. 3. (a) Modelling of the VB bending in a Pt NP/p$\mathrm{Si} /$ Electrolyte device during MACE. The Pt NP was modelled by a $50 \mathrm{~nm}$ wide segment and buried at $1 \mu \mathrm{m}$ from the surface. A polarization of $+0.2 \mathrm{~V}$ is applied to the Pt. Dashed lines indicate the limit of the SCR. (b) Scheme of cone-shaped pore formation by MACE with $\mathrm{Pt}$ NPs underlining $\mathrm{h}^{+}$injections and porous $\mathrm{Si}$ formation as deduced from the modelling. Bold $\mathrm{h}^{+}$are injected carriers, italic $\mathrm{h}^{+}$majority carriers driven through bulk polarization.

By applying a polarization to the Si sample during MACE it is possible to modulate the formation of porous $\mathrm{Si}$ along the macropores and thus to modify the cone angle defined by the porous Si/c-Si interface [3]. Figure 4(a) and 4(b) shows SEM images of a sample surface morphology after MACE under positive bias and porous Si removal in $\mathrm{HNO}_{3} / \mathrm{HF}$ 99:1 V:V (5 $\min )$. Well-defined cone-shaped pores with an angle of $\sim 35^{\circ}$, corresponding to an aspect ratio $(\mathrm{D} / \mathrm{W})$ of 1.6 , cover the whole sample surface.
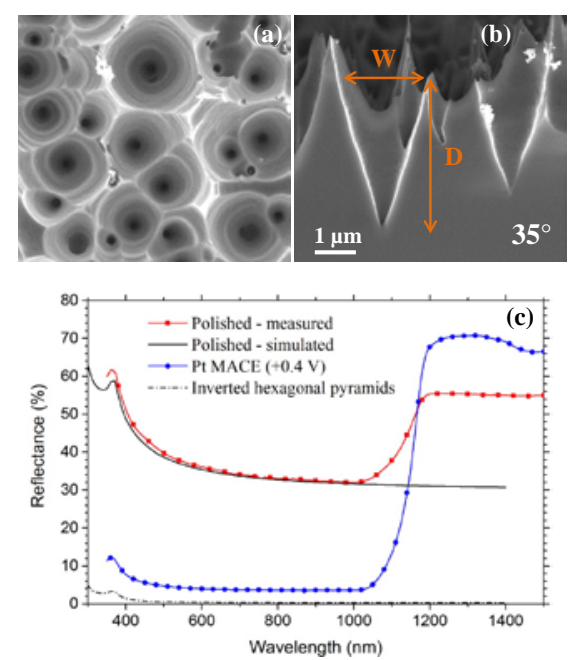

Fig. 4. (a) and (b) Plain and cross sectional SEM images of (100) ptype Si samples after MACE with Pt NPs under positive bias and porous $\mathrm{Si}$ removal in $\mathrm{HNO}_{3} / \mathrm{HF}$. (c) Experimental (red squares and blue circles) and modelled (black solid and dashed lines) reflectance values obtained for polished and MACE texturized Si.

We have found that these structures advantageously reduce the surface reflectance down to $4 \%$ in the $600-1000 \mathrm{~nm}$ range, which compares favorably with state of the art texturization techniques for $\mathrm{Si}$ such as inverted square based pyramids arrays ( $\mathrm{R} \sim 9 \%$ ) used in record efficiency solar cells [5]. Because such morphologies are difficult to obtain even with advanced plasma etching techniques, MACE with Pt has a strong potential for Si surface structuration.

\section{B. Surface structuration of n-type Silicon by MACE using nanoporous Au electrodes}

From a band bending point of view, the use of n-type $\mathrm{Si}$ substrates is more suitable for having a localized etching. For low work function metals such as $\mathrm{Pt}$ and $\mathrm{Au}$, a schottky junction is obtained at the level of the NPs/n-Si electrolyte, and so delocalized etching with porous $\mathrm{Si}$ formation is minimized. Having a lower work function than $\mathrm{Pt}, \mathrm{Au}$ is also more advantageous with this respect. Based on these observations, a new strategy to achieve pattern transfer into $\mathrm{Si}$ by electrochemical MACE with large dimensions metal tools is presented in Figure 5 (a). Previous attempts of Si imprinting with bulk metal electrodes have evidenced limitations due to electrolyte blockage. Here, the problem is solved by using for the first time patterned nanoporous $\mathrm{Au}$ (np-Au) electrodes that allow the electrolyte to access the entire Si/Metal interface. The surface pattern consists in an array of square based 
pyramids, as shown in Figure 5(b), 5(c). We aim at imprinting this pattern to obtain eventually inverted pyramids that are well known for their efficient antireflection properties.

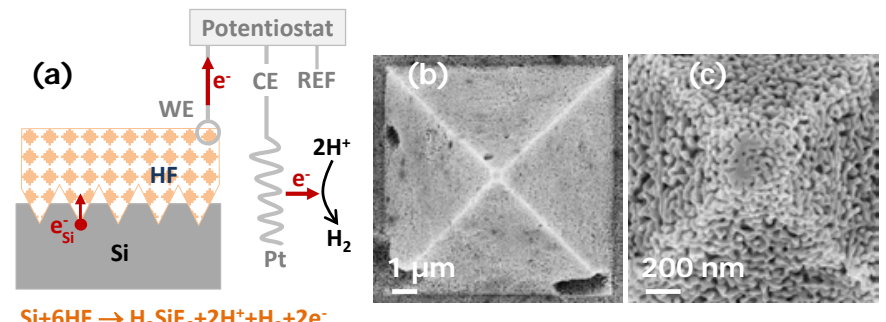

Fig. 5. (a) Scheme of the electrochemical MACE with patterned np$\mathrm{Au}$ electrodes. (a) a np-Au pyramid after dealloying. (b) the np-Au structure at its tip.

The patterned np-Au electrode is positively bias (0.3 V/SME) in HF 5M ( $2 \%$ Ethanol) in the dark and brought into contact with the n-Si under a pressure of $18 \mathrm{~g} \mathrm{~cm}^{-2}$. More details about the experimental set-up can be found in reference [6]. Figure 6 gives SEM images of the results after imprinting for $10 \mathrm{~min}$ in these conditions. The imprinted area is $\sim 1 \mathrm{~mm}^{2}$.

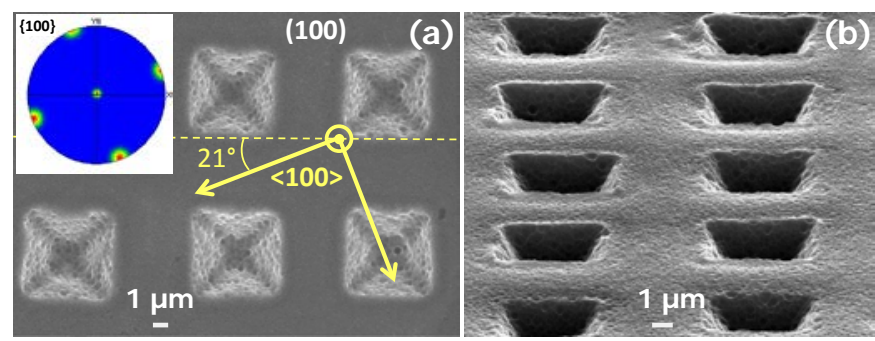

Fig. 6. SEM images of n-type (100) Si surface after imprinting inverted pyramids by MACE. The inset of (a) is a pole figure established by EBSD at $70^{\circ}$ from image (b).

Relatively well defined inverted pyramids are obtained, with dimensions of $5 \times 5 \mu \mathrm{m}^{2}$ and $3.6 \mu \mathrm{m}$ in depth. The inset of Fig. 4(c) shows the pole figure established by Electron Back Scattered Diffraction (EBSD) of the (100) Si crystal. The pyramid sides are clearly not aligned with the [001] and [010] directions of the sample, which is to be expected since the npAu electrode was randomly positioned on the sample surface. The same np-Au electrode could be used several times before the pyramidal pattern was damaged. Current efforts are being devoted to improve resolution, etch rate and imprinted area. One of the goals is to achieve in this way the texturization of multicrystalline Si surface with inverted pyramids.

In this particular MACE configuration, 2D simulations of the valence band modulation at the level of the $\mathrm{Au} / \mathrm{n}-\mathrm{Si}$ contacts have also been performed. Figure 7 shows the valence band energy at the interface of 3 nanoscaled contacts spaced so as to mimic the $\mathrm{Au}$ ligaments in the $\mathrm{np}-\mathrm{Au}$ electrode. This can help to determine the influence of the porosity on the pattern transfer and the extent of delocalized etching, depending on the nature of the metal, the Si doping type and the applied polarization.

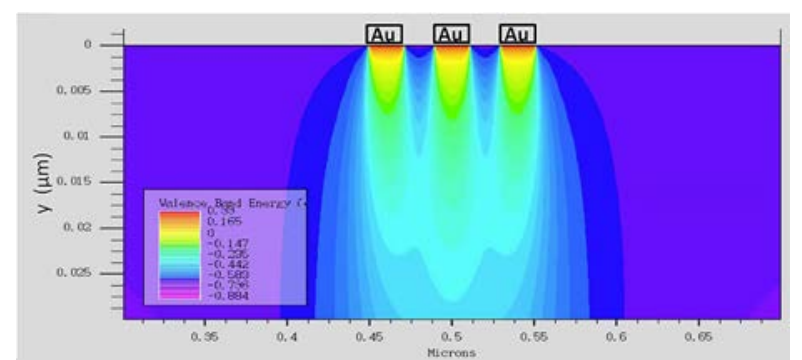

Fig. 7. Valence band energy at three $\mathrm{Au} / \mathrm{n}-\mathrm{Si}$ contacts in the configuration of MACE with a polarized np-Au electrode.

\section{CONCLUSION}

In this work, we have presented two new routes of Si surface texturization by MACE with foreseen photovoltaic applications. These methods rely on the dependence of the (de)localized character of etching with the properties of the metal/Si contacts, which has been extensively studied by 2D band bending modelling of metal/Si/electrolyte interfaces at the nanoscale.

With Pt NPs and p-Si, macroscopic cone-shaped pores in the 1-5 $\mu \mathrm{m}$ size range with a high aspect ratio $(\mathrm{L} / \mathrm{W} \sim 1.6)$ have been obtained by MACE assisted with an external polarization. This morphology leads to a reduction of the surface reflectance below $5 \%$ over the entire visible-near infrared domain. With patterned np-Au electrodes and n-Si, direct imprinting of well-defined arrays of inverted pyramids has been achieved for the first time by electrochemical MACE. The surface pattern of the electrodes is partially transferred to the Si substrate, with a sub-micrometer resolution and independently of the crystallographic orientation. This is a step forward in the development of a texturization method for photovoltaic applications.

\section{ACKNOWLEDGMENTS}

The authors acknowledge the support of the French Agence Nationale de la Recherche (ANR), under grant ANR-14CE07-0005-01 (PATTERN project).

\section{REFERENCES}

[1] Z. Huang, N. Geyer, P. Werner,; J. de Boor, U. Gosele, "MACE of Silicon: A Review”. Adv. Mater. 23, 285-308 (2011).

[2] K. Tsujino, M. Matsumura, " Boring Deep Cylindrical Nanoholes in Silicon Using Silver Nanoparticles as a Catalyst.” Adv. Mater. 17, 1045-1047 (2005).

[3] E. Torralba, S. Le Gall, R. Lachaume, V. Magnin, J. Harari, M. Halbwax, J-. P. Vilcot, C. Cachet-Vivier, and S. Bastide, "Tunable Surface Structuration of Silicon by MACE with Pt NPs under Electrochemical Bias” ACS Appl. Mater. Interfaces 8, 31375 (2016).

[4] K. W. Kolasinski, "The Mechanism of Galvanic / metalAssisted Etching of Silicon.” Nanoscale Res. Lett. 9, 1-8, 2014. 
[5] E. Franklin, K. Fong, K. McIntosh, A. Fell, et. al. "Design, Fabrication and Characterisation of a 24.4\% Efficient Interdigitated Back Contact Solar Cell.” Prog. Photovolt. Res. Appl. 24, 411 (2016)

[6] E. Torralba, M. Halbwax, T. El Assimi, M. Fouchier, V. Magnin, J. Harari, J-. P. Vilcot, S. Le Gall, R. Lachaume, C.
Cachet-Vivier, and S. Bastide, "3D patterning of Silicon by contact etching with anodically biased nanoporous gold electrodes” accepted in Electrochem. Comm. (2017). 